OPEN ACCESS

Edited by:

Horace Massa,

Geneva University Hospitals (HUG), Switzerland

Reviewed by:

Rosane Castro,

State University of Campinas, Brazil

Francesco D'Oria,

Azienda Ospedaliero Universitaria

Consorziale Policlinico di Bari, Italy

*Correspondence:

Mee Kum Kim

kmk9@snu.ac.kr

Specialty section:

This article was submitted to

Ophthalmology,

a section of the journal

Frontiers in Medicine

Received: 08 November 2021

Accepted: 31 January 2022

Published: 01 March 2022

Citation:

Wy S, Kim YK, Jeoung JW and Kim MK (2022) Clinical Outcomes in Maximum Tolerated Medical Therapy

in Penetrating Keratoplasty for Bullous

Keratopathy. Front. Med. 9:810848.

doi: 10.3389/fmed.2022.810848

\section{Clinical Outcomes in Maximum Tolerated Medical Therapy in Penetrating Keratoplasty for Bullous Keratopathy}

\author{
Seoyoung Wy ${ }^{1,2}$, Young Kook Kim ${ }^{1,2}$, Jin Wook Jeoung ${ }^{1,2}$ and Mee Kum Kim ${ }^{1,2,3 *}$ \\ ${ }^{1}$ Department of Ophthalmology, Seoul National University College of Medicine, Seoul, South Korea, ${ }^{2}$ Department of \\ Ophthalmology, Seoul National University Hospital, Seoul, South Korea, ${ }^{3}$ Laboratory of Ocular Regenerative Medicine and \\ Immunology, Biomedical Research Institute, Seoul National University Hospital, Seoul, South Korea
}

Purpose: To compare the clinical outcomes of maximum tolerated medical therapy (MTMT) in patients with penetrating keratoplasty (PKP) with those of Ahmed glaucoma valve (AGV) implantation.

Methods: The medical records were retrospectively reviewed in patients who had undergone PKP for bullous keratopathy and were treated with MTMT or AGV implantation for the management of glaucoma. A total of 18 bullous keratopathic patients were investigated between January 2010 and February 2017: 9 patients treated with MTMT and 9 patients treated with AGV implantation. Non-corrected visual acuity (NCVA), intraocular pressure (IOP), endothelial cell density (ECD), hexagonality, coefficient of variation (CV), central corneal thickness (CCT), median survival time of the graft, and the presence of epithelial keratopathy were compared between the groups at each time point or between baseline and after treatment of glaucoma in each group.

Results: There were no significant differences in the visual acuity and corneal thickness between the two groups or within each group over time. Both groups showed a significant reduction in IOP compared with the baseline IOP, and IOP reductions were greater in the AGV group than in the MTMT group $(p=0.040)$. Significant ECD reductions were found in each group between the baseline and 6 months $(p=0.008$ in the MTMT group, $p=0.015$ in the AGV group); however, no differences were found between the two groups until 12 months. The significant hexagonality reduction was found in the AGV group between the baseline and 12 months $(p=0.018)$. The median survival time showed no significant difference in the survival analysis.

Conclusions: Maximum tolerated medical therapy in penetrating keratoplasty for bullous keratopathy seems to similarly affect the endothelial cell density or graft survival when compared with at least 12 month-followed Ahmed glaucoma valve implantation.

Keywords: Ahmed glaucoma valve, cornea, endothelial cell, maximum tolerated medical therapy, penetrating keratoplasty 


\section{INTRODUCTION}

Glaucoma is a well-known risk factor for corneal endothelial decompensation after penetrating keratoplasty (1-4). Both uncontrolled intraocular pressure (IOP) and Ahmed glaucoma valve (AGV) implantation may affect the endothelial cell decompensation of the graft $(1,5)$. To avoid endothelial damage associated with AGV implantation, maximum tolerated medical therapy (MTMT) can be maintained in patients with glaucoma after penetrating keratoplasty (PKP). Although the graft survival with anti-glaucoma medication was reported to be lower in PKP than that without glaucoma (6), the long-term effect of MTMT on the graft survival or endothelial cell density (ECD) has not been clearly established.

Evidence suggests that the topical anti-glaucoma medication is not directly involved in the reduction of ECD in patients with glaucoma patients (7) or corneal donor grafts (8). However, the long-term use of topical anti-glaucoma medication induces significant ocular surface changes in patients who underwent PKP, such as dry eye, superficial punctate keratitis, conjunctival scarring, and ocular surface inflammation (9-13), which may affect not only the success of subsequent glaucoma surgery but also graft survival. These toxic effects on the ocular surface may be attributed to multiple factors, such as preservatives, low $\mathrm{pH}$, or active ingredients per se (11). Ocular surface damage with topical anti-glaucoma medication may lead to poor compliance, resulting in either less-controlled or fluctuated IOP. Given recent confocal microscopic findings showing a significant increase in the density of dendritic cells with topical anti-glaucoma medication (9), the long-term MTMT may also affect the graft rejection in the early period. Considering that the rapid reduction of ECD in PKP (7.5\%/year) compared with that in normal cornea $(0.6 \%$ /year) over time $(14,15)$, MTMT may also affect the overall graft survival in the compromised cornea due to PKP. Therefore, this study aimed to compare the effect of MTMT with that of AGV implantation on the changes in endothelial cell density (ECD), hexagonality, CV, or the survival of grafts in patients who underwent PKP for a bullous keratopathy.

\section{MATERIALS AND METHODS}

\section{Patient Selection}

This retrospective study was approved by the Institutional Review Board of Seoul National University College of Medicine (IRB No. 1905-038-1031, Seoul, South Korea) and adhered to the tenets of the Declaration of Helsinki. We retrospectively reviewed medical records of patients who were treated with PKP, such as re-PKP, for bullous keratopathy and MTMT or AGV implantation for the management of glaucoma following PKP. The study included patients who were followed-up for at least 12 months after MTMT or AGV implantation at the cornea clinic in Seoul National University Hospital between January 2010 and February 2017. The choice of AGV implantation was determined by the clinical judgment of two glaucoma specialists (Y. K. Kim and J. W. Jeoung), when the IOP was unacceptably high even with MTMT based on the visual field defect status and the severity/or progression of the optic nerve damage in each
TABLE 1 | Demographics of the patients in the MTMT and AGV groups.

\begin{tabular}{lccc}
\hline & MTMT & AGV & P-value* \\
\hline Number of patients & 9 & 9 & \\
Age (years) & $66.1 \pm 12.4$ & $60.9 \pm 12.8$ & 0.489 \\
& $(47-79)$ & $(35-73)$ & \\
Sex (male: female) & $8: 1$ & $7: 2$ & 0.527 \\
Laterality (right: left) & $4: 5$ & $5: 4$ & 0.637 \\
No. of re-PKP & $3(33.3 \%)$ & $1(11 \%)$ & 0.576 \\
Time interval between PKP and & $12.4 \pm 9.9$ & $23.8 \pm 21.7$ & 0.340 \\
onset of anti-glaucoma & $(3-23)$ & $(1-58)$ & \\
treatment (months) & & & \\
Follow-up duration (months) & $34.2 \pm 17.8$ & $50.4 \pm 40.0$ & 0.546 \\
& $(4-67)$ & $(4-113)$ & \\
\hline
\end{tabular}

*Using the Mann-Whitney test or the Fisher's exact test or the Chi-square test where appropriate.

Data was presented as Mean $\pm S D$ (ranges).

MTMT, maximum tolerated medical therapy; AGV, Ahmed glaucoma valve; PKP, penetrating keratoplasty.

patient. The exclusion criteria were as follows: the patients who had diagnosed with other corneal disease with glaucoma, who had undergone any other intraocular surgeries within 6 months before PKP, who had undergone any other intraocular surgeries between PKP and AGV implantation, who had undergone any other intraocular surgeries during MTMT in PKP, and who had not regular examination.

The study included a total of 18 patients: 9 patients who had MTMT and 9 patients who underwent AGV implantation. The demographics of the patients in each group were shown in Table 1. The patients who had undergone re-PKP before AGV were also included in both groups (3 patients in the MTMT group and 1 patient in the AGV group). The proportions of rePKPs did not show a statistically significant difference between the groups. The mean age of patients in the MTMT and AGV groups was 66.1 years (47-79 years) and 60.9 years (35-75 years), respectively. The mean time intervals between PKP and the onset of anti-glaucoma treatment were 12.4 months (323 months) and 23.8 months (1-58 months) in the MTMT and the AGV groups $(p>0.05)$, respectively. The mean follow-up durations were 36.6 months (4-67 months) and 36.9 months (4-113 months) in the MTMT and the AGV groups, respectively. There were no statistically significant differences in all demographic characteristics.

\section{Surgical Procedures and MTMT}

Penetrating keratoplasty was conducted by a single corneal surgeon (M. K. Kim) with 10-0 interrupted sutures, and the lens extraction combined with intraocular lens insertion was performed in 1 eye in the AGV group.

Ahmed glaucoma valve implantation was performed on the superotemporal aspect of each eye. A traction suture through the clear cornea was used in the upper peripheral cornea to enhance the exposure to the surgical field. A 5-mm circumferential and vertical incision was made in the conjunctiva and Tenon's capsule, $1 \mathrm{~mm}$ posterior to the corneal limbus, followed by a 
TABLE 2 | The types of combinations of anti-glaucoma medications used in the MTMT and AGV groups.

\begin{tabular}{|c|c|c|c|}
\hline Anti-glaucoma medications & MTMT & AGV & $P$-value* \\
\hline \multirow[t]{3}{*}{ The types of combinations } & $\begin{array}{l}2 \% \text { dorzolamide } / 0.5 \% \text { timolol }+0.15 \% \\
\text { brimonidine }+0.005 \% \text { latanoprost }+ \text { oral } \\
\text { acetazolamide }\end{array}$ & $\begin{array}{l}2 \% \text { dorzolamide } / 0.5 \% \text { timolol }+0.15 \% \\
\text { brimonidine }+0.005 \% \text { latanoprost }+ \text { oral } \\
\text { acetazolamide }\end{array}$ & \\
\hline & $\begin{array}{l}2 \% \text { dorzolamide } / 0.5 \% \text { timolol }+0.15 \% \\
\text { brimonidine }+0.004 \% \text { travoprost }+ \text { oral } \\
\text { acetazolamide }\end{array}$ & $\begin{array}{l}1 \% \text { brinzolamide } / 0.5 \% \text { timolol }+0.15 \% \\
\text { brimonidine }+0.005 \% \text { latanoprost }+ \text { oral } \\
\text { acetazolamide }\end{array}$ & \\
\hline & $\begin{array}{l}2 \% \text { dorzolamide } / 0.5 \% \text { timolol }+0.5 \% \\
\text { apraclonidine }+0.004 \% \text { travoprost }+ \text { oral } \\
\text { acetazolamide }\end{array}$ & $\begin{array}{l}2 \% \text { dorzolamide }+0.2 \% \\
\text { brimonidine/ } 0.5 \% \text { timolol }+0.004 \% \\
\text { travoprost }+ \text { oral acetazolamide }\end{array}$ & \\
\hline Mean number & $3.5 \pm 1.3(2-5)$ & $4.1 \pm 0.9(3-5)$ & 0.387 \\
\hline
\end{tabular}

*Using the Mann-Whitney test.

MTMT, maximum tolerated medical therapy; AGV, Ahmed glaucoma valve.

dissection between the Tenon's capsule and the sclera. The body of the AGV (model S2 with a surface area of $184 \mathrm{~mm}^{2}$; New World Medical, Rancho Cucamonga, CA, USA) was inserted under the Tenon's capsule between the superior rectus muscle and the lateral rectus muscle. The body of the AGV was fixed to the sclera by two 8-0 prolene (Ethicon, Inc.) anchoring sutures at the front edge of the plate bilaterally, $8-9 \mathrm{~mm}$ from the corneal limbus. An anterior chamber puncture, parallel with the iris surface, was made $1 \mathrm{~mm}$ posterior to the corneal limbus, using a 23-gauge needle. A silicone tube was cut and $\sim 2 \mathrm{~mm}$ was inserted into the anterior chamber, in a bevel-up position. The silicon tube near the corneal limbus was covered using a $4 \mathrm{~mm}$ $\times 3 \mathrm{~mm}$ half-thickness sclera flap. The surgery was completed using continuous running sutures of the Tenon's capsule and the conjunctiva.

Maximum tolerated medical therapy was defined as the use of two or more of the following medications for lowering IOP; topical carbonic anhydrase inhibitor (CAI) (2\% dorzolamide or $1 \%$ brinzolamide), topical beta-blocker ( $0.5 \%$ timolol), topical alpha-agonist $(0.15 \%$ brimonidine, or $0.2 \%$ brimonidine, or $0.5 \%$ apraclonidine), topical prostaglandin analog ( $0.005 \%$ latanoprost or $0.004 \%$ travoprost), and oral administration of acetazolamide. Table 2 summarizes the representative types of combinations of anti-glaucoma medications used in each group. The number of anti-glaucoma medications was not statistically different between those two groups.

\section{Clinical Evaluation}

Data, such as demographics, type of glaucoma treatment, non-corrected visual acuity (NCVA), IOP, ECD, central corneal thickness (CCT), number of anti-glaucoma medications, presence of epithelial keratopathy, and graft survival, were collected. ECD was measured via a non-contact specular microscopy (SP-8800, Konan, Hyogo, Japan). CCT was measured using a pachymeter (Pocket II, Quantel Medical, Paris, France), and IOP was measured using a rebound tonometer (Icare ${ }^{\circledR}$ PRO, Icare Finland Oy, Helsinki, Finland). Graft failure was assessed through slit-lamp examination by the cornea specialist who performed PKP. We defined "graft failure" as the persistent corneal edema when the corneal edema did not disappear within 2 months of immunosuppressive treatment.

\section{Data Analysis}

Each parameter was evaluated before anti-glaucoma treatment (AGV implantation vs. MTMT) and at intervals of 6 and 12 months after the anti-glaucoma treatment. NCVA, IOP, ECD, CCT, and number of anti-glaucoma medications were compared between the AGV and MTMT groups at each time point (intergroup analysis), and compared between the baseline and 6 or 12 months after the anti-glaucoma treatment in each group (intra-group analysis). Graft survival was analyzed and compared between the two groups.

\section{Statistical Analysis}

A statistical analysis was performed using SPSS 20.0 (SPSS Inc., Chicago, IL, USA). The Mann-Whitney test was used to compare each of the parameters at the baseline and after treatment between AGV and MTMT groups and categorical variables were compared using Fisher's exact test or chi-square test (inter-group analysis). The Wilcoxon signed-rank test was used to compare parameters between the baseline and after treatment in each group (intra-group analysis). Graft survival was analyzed using the Kaplan-Meier method to estimate the median survival time (MST). The log-rank test was used to assess the significant differences in MST between the groups. A value of $p<0.05$ was considered statistically significant for all tests.

\section{RESULTS}

Table 3 summarizes baseline parameters in each group before AGV implantation. The mean baseline IOPs were 24.0 (range, 15-42) and 32.6 (range, 21-56) mmHg in the MTMT and the AGV groups $(p>0.05)$, respectively. The mean size of the donor graft was $7.88 \pm 0.18$ (range, $7.25-8.25$ ) $\mathrm{mm}$ in the MTMT group, and $7.72 \pm 0.29$ (range, 7.75-8.25) $\mathrm{mm}$ in the AGV group, which showed no statistical significance. There were no statistically significant differences in ECD, CV, and hexagonality between those two groups. 
TABLE 3 | Clinical characteristics in the MTMT and AGV groups before AGV implantation.

\begin{tabular}{|c|c|c|c|}
\hline & MTMT & AGV & $P$-value* \\
\hline \multicolumn{4}{|l|}{ Baseline ocular parameters } \\
\hline Visual acuity (logMAR) & $\begin{array}{l}1.6 \pm 1.1 \\
(0.7-3.7)\end{array}$ & $\begin{array}{l}1.6 \pm 1.0 \\
(0.7-3.7)\end{array}$ & 0.931 \\
\hline $\begin{array}{l}\text { Intraocular pressure } \\
(\mathrm{mmHg})\end{array}$ & $\begin{array}{c}24.0 \pm 8.6 \\
(15-42)\end{array}$ & $\begin{array}{c}32.6 \pm 10.3 \\
(21-56)\end{array}$ & 0.063 \\
\hline $\begin{array}{l}\text { Endothelial cell density } \\
\left(/ \mathrm{mm}^{2}\right)\end{array}$ & $\begin{array}{c}1683.4 \pm 531.3 \\
(1,259-2,564)\end{array}$ & $\begin{array}{c}1879.8 \pm 1096.9 \\
(343-3,663)\end{array}$ & 0.605 \\
\hline $\begin{array}{l}\text { Central corneal } \\
\text { thickness ( } \mu \mathrm{m})\end{array}$ & $\begin{array}{c}538.1 \pm 42.8 \\
(465-595)\end{array}$ & $\begin{array}{c}556.7 \pm 59.6 \\
(466-908)\end{array}$ & 0.931 \\
\hline Coefficient of variation & $\begin{array}{c}36.8 \pm 5.4 \\
(25-43)\end{array}$ & $\begin{array}{c}34.0 \pm 8.2 \\
(23-46)\end{array}$ & 0.409 \\
\hline Hexagonality (\%) & $\begin{array}{c}57.7 \pm 10.2 \\
(42-74)\end{array}$ & $\begin{array}{c}55.0 \pm 13.5 \\
(33-67)\end{array}$ & 0.644 \\
\hline $\begin{array}{l}\text { Lens status } \\
\text { (phakia: pseudophakia: } \\
\text { aphakia) }\end{array}$ & $0: 7: 2$ & $1: 8: 0$ & 0.471 \\
\hline \multicolumn{4}{|c|}{ Factors associated with PKP } \\
\hline $\begin{array}{l}\text { Combined cataract } \\
\text { extraction }\end{array}$ & $0(0 \%)$ & $1(11 \%)^{+}$ & 0.303 \\
\hline Donor graft size (mm) & $\begin{array}{l}7.88 \pm 0.18 \\
(7.75-8.25)\end{array}$ & $\begin{array}{l}7.72 \pm 0.29 \\
(7.25-8.25)\end{array}$ & 0.190 \\
\hline
\end{tabular}

*Using the Mann-Whitney test or the Fisher's exact test or the chi-square test where appropriate.

$+P K P$ combined with simultaneous cataract surgery was undergone 3 years prior to AGV implantation.

Data were presented as mean $\pm S D$ (ranges).

MTMT, maximum tolerated medical therapy; AGV, Ahmed glaucoma valve; PKP, penetrating keratoplasty.

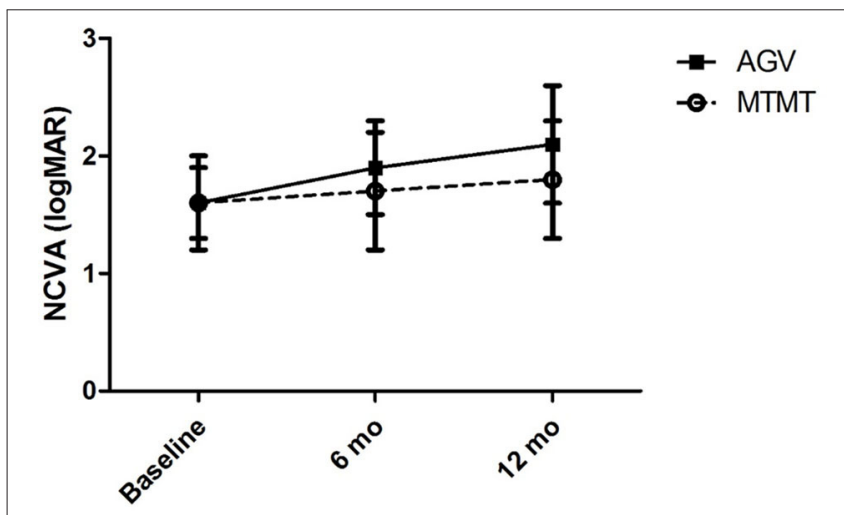

FIGURE 1 | Changes in the non-corrected visual acuity (NCVA) after glaucoma treatment. No significant difference was found between the two groups, and between before and after the treatment in each group.

The visual acuities before the anti-glaucoma treatment, and at 6 and 12 months after the treatment are presented in Figure 1. The mean visual acuities before the treatment, and at 6 and 12 months after the treatment were $1.6 \pm 1.1$ (range, 0.7-3.7), $1.7 \pm$ 1.4 (range, 0.4-4.7), and $1.8 \pm 1.5$ (range, 0.4-4.7) $\log$ MAR units in the MTMT group, and $1.6 \pm 1.0$ (range, 0.7-3.7), $1.9 \pm 1.3$ (range, 0.5-4.7), and $2.1 \pm 1.4$ (range, 0.5-4.7) logMAR units in

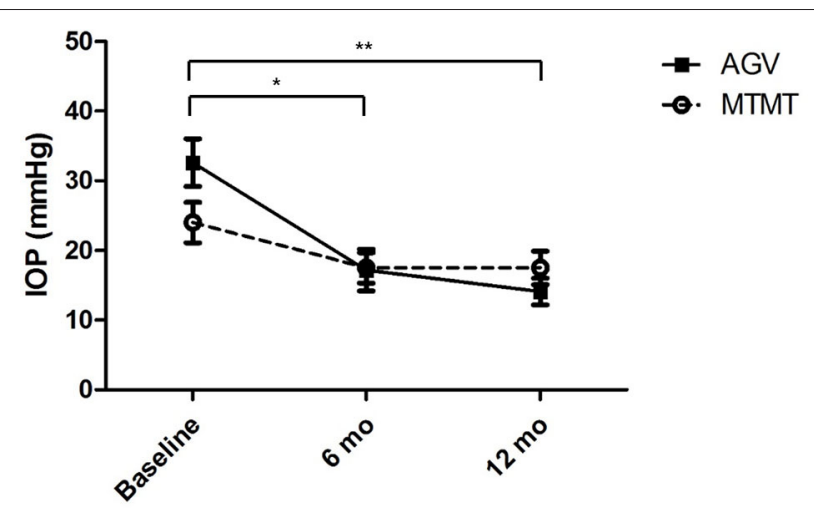

FIGURE 2 | Changes in intraocular pressure (IOP) after anti-glaucoma treatment. No significant difference was found between the two groups. There were significant IOP reductions in the AGV group between baseline and 6 or 12 months after the treatment $\left({ }^{*} p=0.020,{ }^{* *} p=0.008\right.$; Wilcoxon signed-rank test for intra-group analysis).

the AGV group. Although, the average VA was worsened by 0.2 $\log$ MAR units after MTMT and by $0.5 \log$ MAR units after AGV, there was no statistically significant difference in each group over the treatment or between two groups at each time point.

The changes in IOP are presented in Figure 2. The mean IOP before, and at 6 and 12 months after the treatment were $24.0 \pm 8.6$ (range, 15-42), $17.5 \pm 6.6$ (range, 10-32), and $17.5 \pm 7.3$ (range, $10-33) \mathrm{mmHg}$ in the MTMT group and $32.6 \pm 10.3$ (range, 2156), $17.2 \pm 5.8$ (range, 10-39), and $14.1 \pm 5.6$ (range, 7-26) $\mathrm{mmHg}$ in the AGV group, respectively. After AGV implantation, there were significant IOP reductions between the baseline and post-operative 6 months $(p=0.020)$ and between the baseline and post-operative 12 months $(p=0.008)$. IOP reductions were greater in the AGV group than in the MTMT group $(p=0.040)$.

The changes in ECD, hexagonality, CV, and central corneal thickness between the two groups are presented in Figures 3, 4. The mean ECD before, and at 6 and 12 months after the treatment were 1,638.4 \pm 531.3 (range, 1,259-2,564), $777.5 \pm$ 321.7 (range 372-1,404), and 588.8 \pm 324.5 (range 331-1,262) cells $/ \mathrm{mm}^{2}$ in the MTMT group, and 1,879.8 $\pm 1,096.9$ (range, 343-3,663), 1,509.3 $\pm 1,291.6$ (range, 504-3,703), and 1,226.0 $\pm 1,227.7$ (range, 606-3,333) cells $/ \mathrm{mm}^{2}$ in the AGV group, respectively. There were significant ECD reductions between the baseline and 6 months after the treatment in both groups (MTMT, $p=0.008$; AGV, $p=0.015$ ), and between the baseline and 12 months after the treatment in the MTMT group ( $p=$ 0.008 ). Notably, there were no statistically significant differences between two groups over time. The mean hexagonality before, and at 6 and 12 months after the treatment were $57.7 \pm 10.2$ (range, 42-74), $53.0 \pm 15.0$ (range, 30-70), and $55.8 \pm 11.3$ (40$71) \%$ in the MTMT group, and $55.0 \pm 13.5$ (range, 33-67), $54.8 \pm$ 13.2 (range, 33-66), and $49.9 \pm 15.2$ (range, 35-75)\% in the AGV group. There was a significant hexagonality reduction between the baseline and 12 months after the treatment in the AGV group $(p=0.018)$, but there were no statistically significant differences in hexagonality between the two groups. The mean CV before, 


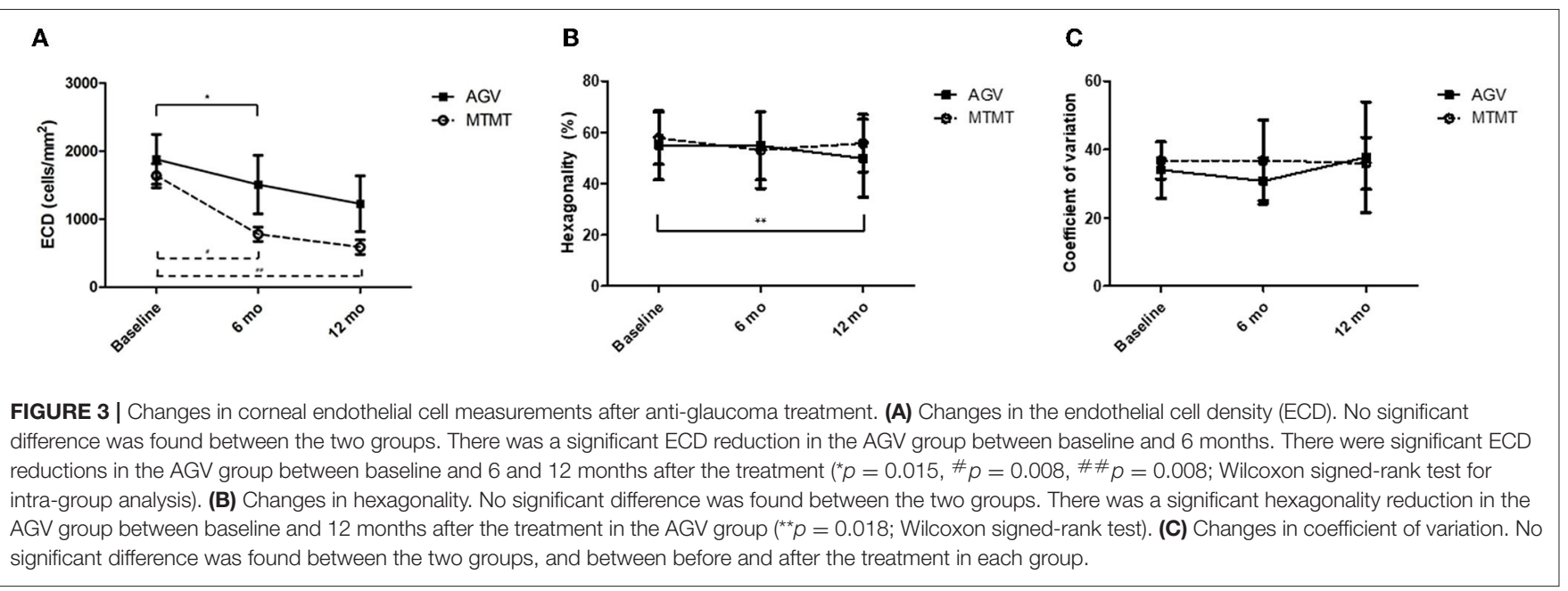

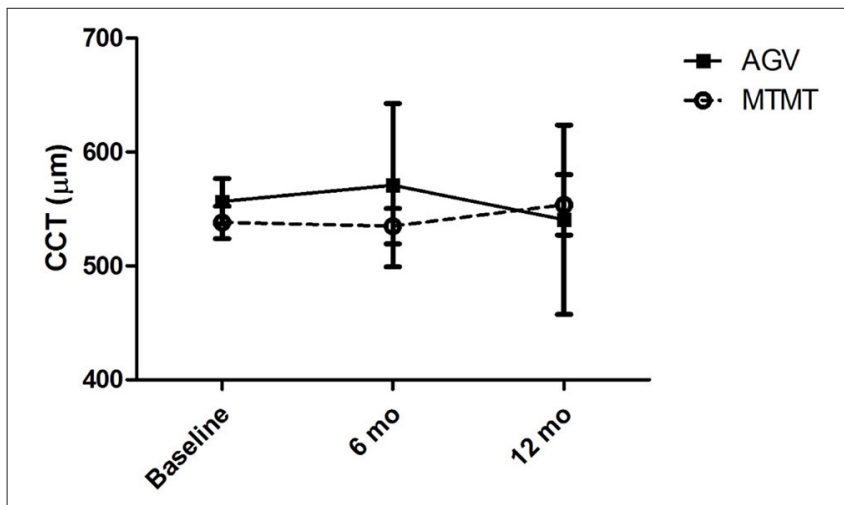

FIGURE 4 | Changes in central corneal thickness (CCT) after anti-glaucoma treatment. No significant difference was found between the two groups, and between before and after the treatment in each group.

and at 6 and 12 months after the treatment were $36.8 \pm 5.4$ (range, 25-43), $36.8 \pm 11.9$ (range 26-64), and $35.9 \pm 7.6$ (range, 40-71) in the MTMT group, and $34.0 \pm 8.2$ (range, 23-46), 30.8 \pm 6.7 (range, 22-46), and $37.7 \pm 16.2$ (range, 26-72) in the AGV group. There were no statistically significant differences in $\mathrm{CV}$ before treatment, and at 6 and 12 months after the treatment in each group and between two groups. The mean corneal thickness before, and at 6 and 12 months after the treatment were $538.1 \pm$ 42.8 (range, 465-595, 534.8 \pm 46.4 (range, 470-623), and 553.6 \pm 79.5 (range, 460-642) $\mu \mathrm{m}$ in the MTMT group, and $556.7 \pm 59.6$ (range, 493-697), 570.8 \pm 108.2 (range, 449-807), and $540.6 \pm$ 83.9 (range, 412-908) $\mu \mathrm{m}$ in the AGV group, respectively. There were no statistically significant differences in corneal thickness before the treatment, and at 6 and 12 months after the treatment in each group and between two groups.

Corneal graft failure occurred in 7 patients $(77.7 \%)$ in the MTMT group and 3 patients (33.3\%) in the AGV group eventually. There were no statistically significant differences between the two groups. The median survival time (MST) was $1,050.0 \pm 575.1$ (range, 120-2,010) days in the MTMT group,

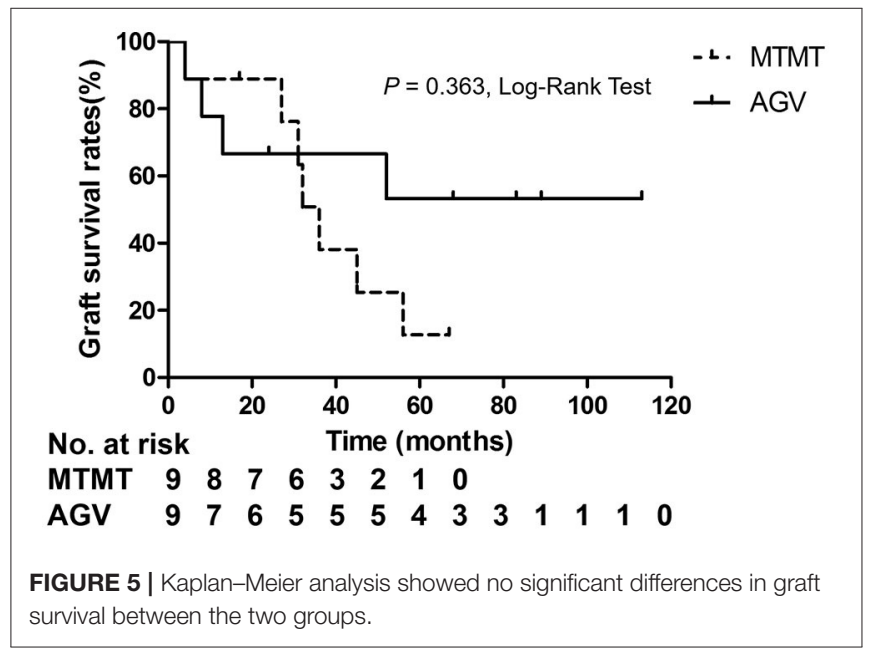

TABLE 4 | Superficial punctate epithelial keratopathy of the corneal grafts in the MTMT and AGV groups.

\begin{tabular}{lcccc}
\hline & & MTMT & AGV & P-value* \\
\hline $\begin{array}{l}\text { Superficial punctate } \\
\text { epithelial keratopathy }\end{array}$ & Yes & 7 & 3 & \\
$\begin{array}{l}\text { No. of patients) } \\
\text { Percentages (\%) }\end{array}$ & No & 2 & 6 & \\
\hline
\end{tabular}

*Using the Fisher's exact test.

MTMT, maximum tolerated medical therapy; AGV, Ahmed glaucoma valve.

and $1,513.3 \pm 1201.4$ (range, 120-3,390) days in the AGV group, which showed no significant difference in the survival analysis $(p$ $=0.363$, log-rank test) (Figure 5). Superficial punctate epithelial keratopathy of the corneal grafts occurred in 10 patients $(77.7 \%)$ in the MTMT group and 3 patients (33.3\%) in the AGV group, and there was no statistically significant difference between the two groups (Table 4). 
TABLE 5 | Number of topical medications in the MTMT and AGV groups.

\begin{tabular}{lccc}
\hline & MTMT & AGV & P-value* \\
\hline Pre-treatment & $3.5 \pm 1.3(2-5)$ & $4.1 \pm 0.9(3-5)$ & 0.387 \\
At 12 months & $3.0 \pm 1.2(2-5)$ & $1.3 \pm 1.7(0-5)$ & 0.024
\end{tabular}

*Using the Mann-Whitney test.

MTMT, maximum tolerated medical therapy; AGV, Ahmed glaucoma valve.

The mean number of anti-glaucoma medications before the treatment and at 12 months after the treatment were 3.5 (range, 2-5) and 3.0 (range, 2-5) in the MTMT group and 4.1 (range, 35) and 1.3 (range, 0-5) in the AGV group (Table 5). There were no differences in the mean number of medications between two groups before the treatment $(p=0.387)$, while the number of medications was significantly lower in the AGV group than in the MTMT group at 12 months $(p=0.024)$.

\section{DISCUSSION}

In this study, effects of $\mathrm{AGV}$ implantation were comparable to effects of MTMT on ECD changes and graft survival in patients with penetrating keratoplasty for at least 12 months. However, surprisingly, the reduction in ECD with MTMT of PKP eyes for bullous keratopathy was greater than those eyes with normal ECD in previous studies $(5,7,16)$. This is the first report to evaluate ECD changes with MTMT in corneal transplanted eyes so far. In previous reports, they described the effect of each antiglaucoma drug on ECD, neither the combined anti-glaucoma drugs nor MTMT. Therefore, it is still noteworthy to report that the effect on ECD can be influenced by both multiple combined topical anti-glaucoma drugs and compromised endothelial cells in the host owing to the transplantation and previous history of bullous keratopathy. In the AGV group, a patient who had undergone PKP combined with simultaneous cataract surgery 3 years prior to AGV implantation was included. Since previous studies have reported that the decrease in ECD after 6 months after cataract surgery was not significant (17-19), the fact that PKP with simultaneous cataract surgery was included in the AGV group would not have affected the outcome of ECD.

Based on previous reports that suggested a graft failure of 8 26\% with AGV implantation at 12 months in patients with penetrating keratoplasty (2, 20-22), our data showed a graft failure of $33 \%$ with AGV implantation, which were comparable with previous reports. The mean loss of ECD was $653 / \mathrm{mm}^{2} /$ year in the $\mathrm{AGV}$, which was comparable with previous reports $(-315$ cells $/ \mathrm{mm}^{2} /$ year) (21) and a recent study has suggested ECD loss of -519.97 cells $/ \mathrm{mm}^{2}$ for 2 years (23). Given that the patients who showed unacceptably high IOP based on their severity or progression of the optic nerve damages or visual field defects had undergone AGV implantation, high pre-operative IOP in AGV, although it was insignificant, may also affect changes of ECD. In this study, hexagonality of corneal endothelial cells significantly decreased after 1 year of AGV implantation, whereas a previous study showed no significant difference in hexagonality after AGV implantation or compared with the control group (24).

Notably, the MTMT group showed a remarkable reduction in ECD $\left(-1,050\right.$ cells $/ \mathrm{mm}^{2} /$ year $)$, which was insignificant compared with the AGV group, but was significant compared with the baseline. The ECD changes with MTMT in glaucoma patients who underwent PKP have yet to be reported probably due to the failure to consider reduction in ECD following MTMT. The effect of topical CAIs on ECD remains controversial. Some clinical studies showed no significant reduction in ECD following the application of topical CAIs in patients with glaucoma who did not undergo intraocular surgery although corneal thickness was increased occasionally $(25,26)$. The other studies show that CAI effect on ECD is primarily related to attenuation of the bicarbonate efflux $(3,4)$. Eye bank data showed no significant correlation of ECD loss with anti-glaucoma medication in the absence of ocular surgery (8). However, the ECD of the donor graft in recipients after PKP may be affected differently by antiglaucoma medications. The annual rate of endothelial cell loss is $0.6 \%$ in the normal adult human cornea (15). By contrast, the compromised cornea after PKP loses endothelial cells at a rate of $7.8-7.9 \%$ per year over 10 years $(14,27,28)$. The endothelial cells can be significantly affected by topical CAIs in compromised corneas with guttata $(29,30)$. Therefore, the longterm MTMT using topical CAIs may affect ECD in compromised corneas as in PKP. In line with this, our study suggested that ECD may be significantly reduced by the long-term MTMT in patients who underwent PKP. Another possibility is that the long-term exposure to higher IOP in MTMT compared with AGV implantation may cause a reduction of ECD. Meanwhile, MTMT did not show any differences in hexagonality and CV. It indicates that the functional attenuation may be less in MTMT when compared with AGV implantation despite the reduction of ECD. Besides, the prevalence of superficial punctate epithelial keratopathy in patients with MTMT was also higher than in patients with AGV. Therefore, we hypothesized how to lose endothelial cells with either MTMT or glaucoma drainage device (Figure 6). With long-term anti-glaucoma medication, endothelial toxicity related to low $\mathrm{pH}$, preservatives of antiglaucoma eyedrops, ocular inflammation related to an ingredient, such as prostaglandin analogs, or CAIs' effects on corneal endothelial transports may contribute to the reduction of endothelial cell density in corneal grafts (Figure 6, upper chart) (30-34). Whereas, turbulent aqueous flow or mechanical stress near the tube seems to contribute directly in the reduction of endothelial cell density in corneal grafts (Figure 6, lower chart) (35). Long-term graft survival with the shunt surgery was known to be lower than that with anti-glaucoma medication (6), whereas damaged ocular surface may end up with poor compliances, and it can induce less-controlled IOP along with the reduced graft survival in MTMT. Given that the prevalence of SPK was more than double in MTMT, although it was not significant, increased SPK may contribute to further ocular surface inflammation or may affect drug compliance. Therefore, AGV implantation can be still considered as an alternative option for patients who require long-term MTMT in the compromised cornea with PKP. 


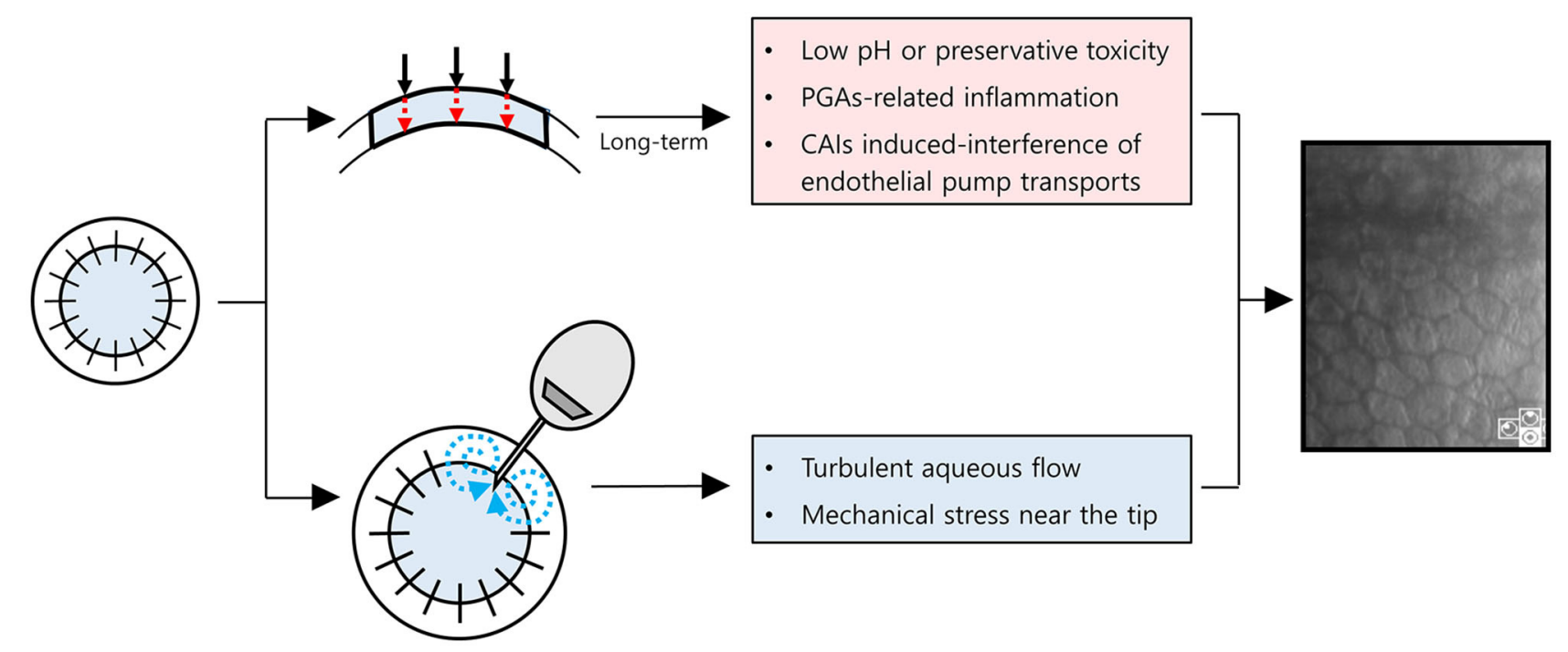

FIGURE 6 | Schematic diagram for a hypothesis on how to damage corneal endothelial cells with maximum tolerated medical therapy or glaucoma drainage device. Red dot arrows indicate anti-glaucoma eyedrops are permeable to endothelial cells with (1) low pH or preservative toxicity, (2) PGAs-related inflammation, or (3) CAls induced-interference of endothelial pump transports. Blue dot arrows indicate turbulent aqueous flow near the tube. PGAs, prostaglandin analogs; CAls, Carbonic anhydrase inhibitors.

Besides, current studies investigated the effect of minimally invasive glaucoma surgery (MIGS) on corneal endothelial cells. The CyPass supraciliary microshunt (Alcon Laboratories, Fort Worth, TX) has been withdrawn from the global marketplace because of its adverse effect on $\operatorname{ECD}(36,37)$. It has been reported that endothelial cell loss at 24 months after the XEN gel stent (Allergan, Belfast, Ireland) implantation was 14.5\% (38). As for the Ex-Press mini-shunt (Alcon Laboratories), endothelial cell loss at 12 months was $10.0 \%$ and at 24 months was $18.0 \%$ in long-term studies $(39,40)$. There are only several case reports describing the effects of MIGS on corneal endothelial cells in post-keratoplasty glaucoma so far, and the results are controversial $(41,42)$.

The study was limited by the small number of cases, the retrospective study design, and the short-term outcome based on 1-year data analysis. Due to the retrospective nature, the study design was failed to show direct head-to-head comparison and randomization of MTMT or AGV implantation was unavailable due to an ethical issue. Although not statistically significant, the mean age of patients in the MTMT group was almost 5 years older than that of the AGV group, pre-operative IOP was high in the AGV group, and the time between PKP and onset of antiglaucoma treatment was almost double that of the MTMT group. These differences may have affected the corneal endothelial cells loss. For the survival analysis, limited follow-up and different follow-up duration may have increased the risk of bias in the comparative survival analysis. Finally, re-PKP in both groups, which was insignificant, may also have affected the survival of the corneal grafts. Therefore, further long-term prospective study is pending.

Although this study is preliminary, it is still worthwhile to reveal the possible endothelial toxicity with long-term MTMT in transplanted corneal graft for previous bullous keratopathy. It indicates that an alternative option with an AGV implantation or MIGS may be required in patients with PKP when the longterm MTMT is mandatory. In summary, MTMT seems to affect the endothelial cell density in patients who underwent PKP for bullous keratopathy, and it appears to be similar to the initial effect of AGV implantation. Therefore, careful monitoring of ECD should be considered in corneal transplanted patients with MTMT for glaucoma.

\section{DATA AVAILABILITY STATEMENT}

The data analyzed in this study is subject to the following licenses/restrictions: The datasets contains patient information and is not publicly available. Requests to access these datasets should be directed to Mee Kum Kim, kmk9@snu.ac.kr.

\section{ETHICS STATEMENT}

The studies involving human participants were reviewed and approved by Institutional Review Board of Seoul National University College of Medicine. Written informed consent for participation was not required for this study in accordance with the national legislation and the institutional requirements.

\section{AUTHOR CONTRIBUTIONS}

$\mathrm{MK}$ is the principal investigator of the study and made substantial contributions to the design for this study and participated in the interpretation of data and the critical 
revision of the manuscript for important intellectual content. SW made substantial contributions to the acquisition of data and analysis of data for this study and drafted the article.
YK and JJ participated in the interpretation of data and the revision of the manuscript. All authors read and approved the final manuscript.

\section{REFERENCES}

1. Liu M, Hong J. Risk factors for endothelial decompensation after penetrating keratoplasty and its novel therapeutic strategies. J Ophthalmol. (2018) 2018:1389486. doi: 10.1155/2018/1389486

2. Elhofi A, Helaly HA. Graft survival after penetrating keratoplasty in cases of trabeculectomy versus ahmed valve implant. J Ophthalmol. (2018) 2018:9034964. doi: 10.1155/2018/9034964

3. Abdelghany AA, D'Oria F, Alio JL. Surgery for glaucoma in modern corneal graft procedures. Surv Ophthalmol. (2021) 66:276-89. doi: 10.1016/j.survophthal.2020.08.002

4. Konowal A, Morrison J, Brown S, Cooke D, Maguire L, Verdier $\mathrm{D}$, et al. Irreversible corneal decompensation in patients treated with topical dorzolamide. Am J Ophthalmol. (1999) 127:403-6. doi: 10.1016/S0002-9394(98)00438-3

5. Yu ZY, Wu L, Qu B. Changes in corneal endothelial cell density in patients with primary open-angle glaucoma. World J Clin Cases. (2019) 7:1978-85. doi: 10.12998/wjcc.v7.i15.1978

6. Stewart RM, Jones MN, Batterbury M, Tole D, Larkin DF, Kaye SB. Effect of glaucoma on corneal graft survival according to indication for penetrating keratoplasty. Am J Ophthalmol. (2011) 151:257-62.e1. doi: 10.1016/j.ajo.2010.08.018

7. Güneş I B, Öztürk H, Özen B. Do topical antiglaucoma drugs affect the cornea? Eur J Ophthalmol. (2021). doi: 10.1177/11206721211016981. [Epub ahead of print].

8. Kwon JW, Rand GM, Cho KJ, Gore PK, McCartney MD, Chuck RS. Association between corneal endothelial cell density and topical glaucoma medication use in an eye bank donor population. Cornea. (2016) 35:1533-6. doi: 10.1097/ICO.0000000000000972

9. Baghdasaryan E, Tepelus TC, Vickers LA, Huang P, Chopra V, Sadda SR, et al. Assessment of corneal changes associated with topical antiglaucoma therapy using in vivo confocal microscopy. Ophthal Res. (2019) 61:51-9. doi: $10.1159 / 000484632$

10. Aguayo Bonniard A, Yeung JY, Chan CC, Birt CM. Ocular surface toxicity from glaucoma topical medications and associated preservatives such as benzalkonium chloride (Bak). Expert Opin Drug Metab Toxicol. (2016) 12:111. doi: 10.1080/17425255.2016.1209481

11. Lee S, Kim MK, Choi HJ, Wee WR, Kim DM. Comparative cross-sectional analysis of the effects of topical antiglaucoma drugs on the ocular surface. $A d v$ Ther. (2013) 30:420-9. doi: 10.1007/s12325-013-0021-8

12. Saini M, Vanathi M, Dada T, Agarwal T, Dhiman R, Khokhar S. Ocular surface evaluation in eyes with chronic glaucoma on long term topical antiglaucoma therapy. Int J Ophthalmol. (2017) 10:931-8. doi: 10.18240/ijo.201 7.06.16

13. Baudouin C. Ocular surface and external filtration surgery: mutual relationships. Dev Ophthalmol. (2017) 59:67-79. doi: 10.1159/000458487

14. Ono T, Ishiyama S, Hayashidera T, Mori Y, Nejima R, Miyata K, et al. twelveyear follow-up of penetrating keratoplasty. Jpn J Ophthalmol. (2017) 61:131-6. doi: 10.1007/s10384-016-0489-2

15. Bourne WM, Nelson LR, Hodge DO. Central corneal endothelial cell changes over a ten-year period. Invest Ophthalmol Visual Sci. (1997) 38:779-82.

16. Vaiciuliene R, Rylskyte N, Baguzyte G, Jasinskas V. risk factors for fluctuations in corneal endothelial cell density (Review). Exp Ther Med. (2022) 23:129. doi: 10.3892/etm.2021.11052

17. Choi JY, Han YK. Long-term ( $\geq 10$ years) results of corneal endothelial cell loss after cataract surgery. Can J Ophthalmol. (2019) 54:438-44. doi: 10.1016/j.jcjo.2018.08.005

18. Storr-Paulsen A, Norregaard JC, Ahmed S, Storr-Paulsen T, Pedersen TH. Endothelial cell damage after cataract surgery: divide-and-conquer versus phaco-chop technique. J Cataract Refract Surg. (2008) 34:996-1000. doi: 10.1016/j.jcrs.2008.02.013

19. Franchini A, Frosini S, Vieri B. Standard coaxial phaco vs. microincision cataract surgery: a corneal endothelium study. Int Eye Sci. (2006) 6:769-74.

20. Tai MC, Chen YH, Cheng JH, Liang CM, Chen JT, Chen CL, et al. Early Ahmed glaucoma valve implantation after penetrating keratoplasty leads to better outcomes in an asian population with preexisting glaucoma. PLOS ONE. (2012) 7:e37867. doi: 10.1371/journal.pone.0037867

21. Akdemir MO, Acar BT, Kokturk F, Acar S. Clinical outcomes of trabeculectomy vs. ahmed glaucoma valve implantation in patients with penetrating keratoplasty: (trabeculectomy vs. Ahmed galucoma valve in patients with penetrating keratoplasty). Int Ophthalmol. (2016) 36:541-6. doi: 10.1007/s10792-015-0160-9

22. Al-Torbak A. Graft survival and glaucoma outcome after simultaneous penetrating keratoplasty and ahmed glaucoma valve implant. Cornea. (2003) 22:194-7. doi: 10.1097/00003226-200304000-00002

23. Kim JY, Lee JS, Lee T, Seo D, Choi W, Bae HW, et al. Corneal endothelial cell changes and surgical results after ahmed glaucoma valve implantation: ciliary sulcus versus anterior chamber tube placement. Sci Rep. (2021) 11:1-9. doi: 10.1038/s41598-021-92420-8

24. Lee E-K, Yun Y-J, Lee J-E, Yim J-H, Kim C-S. Changes in corneal endothelial cells after Ahmed glaucoma valve implantation: 2-year follow-up. Am J Ophthalmol. (2009) 148:361-7. doi: 10.1016/j.ajo.2009.04.016

25. Inoue $\mathrm{K}$, Okugawa $\mathrm{K}$, Oshika $\mathrm{T}$, Amano $\mathrm{S}$. Influence of dorzolamide on corneal endothelium. Jpn J Ophthalmol. (2003) 47:129-33. doi: 10.1016/S0021-5155(02)00667-6

26. Nakano T, Inoue R, Kimura T, Suzumura H, Tanino T, Yamazaki Y, et al. Effects of brinzolamide, a topical carbonic anhydrase inhibitor, on corneal endothelial cells. Adv Ther. (2016) 33:1452-9. doi: 10.1007/s12325-016-0373-y

27. Ing JJ, Ing HH, Nelson LR, Hodge DO, Bourne WM. Ten-year postoperative results of penetrating keratoplasty. Ophthalmology. (1998) 105:1855-65. doi: 10.1016/S0161-6420(98)91030-2

28. Lass JH, Benetz BA, Gal RL, Kollman C, Raghinaru D, Dontchev M, et al. Donor age and factors related to endothelial cell loss 10 years after penetrating keratoplasty: specular microscopy ancillary study. Ophthalmology. (2013) 120:2428-35. doi: 10.1016/j.ophtha.2013.08.044

29. Epstein RJ, Brown SV, Konowal A. Endothelial changes associated with topical dorzolamide do appear to be significant. Arch Ophthalmol. (2004) 122:1089. doi: 10.1001/archopht.122.7.1089-b

30. Wirtitsch MG, Findl O, Kiss B, Petternel V, Heinzl H, Drexler W. Shortterm effect of dorzolamide hydrochloride on central corneal thickness in humans with cornea guttata. Arch Ophthalmol. (2003) 121:621-5. doi: 10.1001/archopht.121.5.621

31. Chwa M, Atilano SR, Reddy V, Jordan N, Kim DW, Kenney MC. Increased stress-induced generation of reactive oxygen species and apoptosis in human keratoconus fibroblasts. Invest Ophthalmol Visual Sci. (2006) 47:1902-10. doi: 10.1167/iovs.05-0828

32. Trzeciecka A, Paterno JJ, Toropainen E, Koskela A, Podracka L, Korhonen E, et al. Long-term topical application of preservative-free prostaglandin analogues evokes macrophage infiltration in the ocular adnexa. Eur J Pharmacol. (2016) 788:12-20. doi: 10.1016/j.ejphar.2016.06.014

33. Yang Y, Huang C, Lin X, Wu Y, Ouyang W, Tang L, et al. 0.005\% Preservativefree latanoprost induces dry eye-like ocular surface damage via promotion of inflammation in mice. Invest Ophthalmol Visual Sci. (2018) 59:3375-84. doi: 10.1167/iovs.18-24013

34. Chen W, Li Z, Hu J, Zhang Z, Chen L, Chen Y, et al. corneal alternations induced by topical application of benzalkonium chloride in rabbit. PLoS ONE. (2011) 6:e26103. doi: 10.1371/journal.pone.0026103

35. Janson BJ, Alward WL, Kwon YH, Bettis DI, Fingert JH, Provencher LM, et al. Glaucoma-associated corneal endothelial cell damage: a review. Surv Ophthalmol. (2018) 63:500-6. doi: 10.1016/j.survophthal.2017.11.002

36. Lass JH, Benetz BA, He J, Hamilton C, Von Tress M, Dickerson J, et al. Corneal endothelial cell loss and morphometric changes 5 years after 
phacoemulsification with or without cypass micro-stent. Am J Ophthalmol. (2019) 208:211-8. doi: 10.1016/j.ajo.2019.07.016

37. FDA. Update: Potential Eye Damage from Alcon Cypass Micro-Stent Used to Treat Open-Angle Glaucoma: Fda Safety Communication (2018).

38. Gillmann K, Bravetti GE, Rao HL, Mermoud A, Mansouri K. Impact of phacoemulsification combined with xen gel stent implantation on corneal endothelial cell density: 2-year results. J Glaucoma. (2020) 29:155-60. doi: 10.1097/IJG.0000000000001430

39. Arimura S, Miyake S, Iwasaki K, Gozawa M, Matsumura T, Takamura Y, et al. Randomised clinical trial for postoperative complications after ex-press implantation versus trabeculectomy with 2-year follow-up. Sci Rep. (2018) 8:1-8. doi: 10.1038/s41598-018-34627-w

40. Lee GY, Lee CE, Lee KW, Seo S. Long-Term Efficacy and Safety of Express Implantation for Treatment of Open Angle Glaucoma. International journal of ophthalmology. (2017) 10:1379.

41. Rahmania N, Rampat R, Moran S, Gatinel D, Grise-Dulac A. Outcomes of gel stent implantation for glaucoma in patients with previous corneal graft surgery: a case series. Cornea. (2020) 39:417-21. doi: 10.1097/ICO.0000000000002253

42. Lippera M, Lippera S, Ferroni P, Pallotta G, Morodei S, Iannone A, et al. Xen gel stent as a minimally invasive option for intraocular pressure control after dsaek: a case study. Eur J Ophthalmol. (2020):1120672120960335. doi: $10.1177 / 1120672120960335$

Conflict of Interest: The authors declare that the research was conducted in the absence of any commercial or financial relationships that could be construed as a potential conflict of interest.

Publisher's Note: All claims expressed in this article are solely those of the authors and do not necessarily represent those of their affiliated organizations, or those of the publisher, the editors and the reviewers. Any product that may be evaluated in this article, or claim that may be made by its manufacturer, is not guaranteed or endorsed by the publisher.

Copyright (c) 2022 Wy, Kim, Jeoung and Kim. This is an open-access article distributed under the terms of the Creative Commons Attribution License (CC BY). The use, distribution or reproduction in other forums is permitted, provided the original author(s) and the copyright owner(s) are credited and that the original publication in this journal is cited, in accordance with accepted academic practice. No use, distribution or reproduction is permitted which does not comply with these terms. 